\title{
Associations of dietary phytosterols with blood lipid profiles and prevalence of obesity in Chinese adults, a cross-sectional study
}

Yan-chuan Li ${ }^{1}$, Chun-long Li ${ }^{2}$, Rui $\mathrm{Li}^{3}$, Yang Chen ${ }^{1}$, Meng Zhang ${ }^{1}$, Pan-pan Guo ${ }^{1}$, Dan Shi ${ }^{1}$, Xiao-ning Ji ${ }^{1}$, Ren-nan Feng ${ }^{1 *}$ and Chang-hao Sun ${ }^{1 *}$

\begin{abstract}
Background: It has been established in RCTs that high dose of phytosterols can significantly reduce blood cholesterol. However, it was uncertain whether low dose of phytosterols from daily diets was effective. In this study, we evaluated the associations between dietary phytosterols and body mass index (BMI), waist circumference (WC), blood glucose, serum lipid profiles and prevalence of overweight/obesity and abdominal obesity in healthy subjects.

Methods: Four hundred nine men and 503 women aged 18-60 years were included in this study. Dietary intakes of phytosterols were estimated using a validated food frequency questionnaire. Height, body weight, WC and blood pressure were measured, an oral glucose tolerance test was performed. Moreover, fasting serum triglyceride (TG), total cholesterol (TC), high density lipoprotein cholesterol (HDLc) and low density lipoprotein cholesterol (LDLC) were further determined.

Results: When comparing extreme quartiles of dietary phytosterols, significant differences of BMI, WC, systolic blood pressure (SBP), diastolic blood pressure (DBP), serum TC and LDLc were found. Dietary phytosterols presented a negative association with BMI, WC, SBP, DBP, serum TC and LDLC (with and without adjustment for energy). After adjustment for confounders, we found higher dietary phytosterols were linked with lower prevalence of overweight/obesity (OR highest vs. lowest quartile $=0.487 ; 95 \% \mathrm{Cl} 0.234,0.918$ for men; OR highest vs. lowest quartile $=0.277 ; 95 \% \mathrm{Cl} 0.124,0.619$ for women) and abdominal obesity (OR highest vs. lowest quartile $=0.344 ; 95 \% \mathrm{Cl} 0.144,0.819$ for men; OR highest vs. lowest quartile $=0.321 ; 95 \% \mathrm{Cl} 0.140,0.571$ for women).
\end{abstract}

Conclusions: Higher dietary phytosterols were associated with lower BMI, WC, blood pressure, serum TC and LDLC and lower prevalence of overweight/obesity and abdominal obesity in Chinese adults.

Keywords: Human, dietary phytosterols, TC, LDLC, Obesity

\section{Background}

Obesity is an increasing challenge for public health in many countries [1], and although elevated body mass index (BMI) is a modifiable risk factor for a series of metabolic disorders and chronic diseases, including insulin resistance [2], metabolic syndrome, type 2 diabetes [3], cardiovascular diseases (CVDs) [2], hypertension [4], dyslipidemia [5], and certain cancers [6], it is difficult to maintain weight loss.

\footnotetext{
*Correspondence: fengrennan@163.com; changhao2002sun@gmail.com ${ }^{1}$ Department of Nutrition and Food Hygiene, School of Public Health, Harbin Medical University, Harbin, People's Republic of China

Full list of author information is available at the end of the article
}

Dietary habits were considered to play a vital role in development, treatment and prevention of chronic diseases, such as obesity, hyperlipidemia, diabetes and CVDs [7-9]. Therefore, it is important to extensively focus on the associations between daily diet and chronic diseases, and reasonable dietary recommendation should be raised.

Plant sterols and plant stanols (together they are referred as phytosterols) are a group of non-nutritive but bioactive compounds naturally present in all plant origin foods, they are 28- or 29-carbon alcohols and their structures are similar to cholesterol, a 27-carbon alcohol [10]. The dominant dietary plant sterols are $\beta$-sitosterol, campesterol, and 
stigmasterol, all have double bonds at the C-5 position of the ring. In certain structures, the double bond is saturated and these compounds are referred as plant stanols. Compared with plant sterols, concentrations of plant stanols, such as $\beta$-sitostanol and campestanol were generally lower in daily foods [11]. Phytosterols are structurally similar to cholesterol and can inhibit cholesterol absorption. Many randomized controlled trials (RCTs) have confirmed that phytosterols added into fat-based foods can significantly reduce serum total cholesterol (TC) and LDL cholesterol (LDLc) [12-14]. A recent meta-analysis including 84 RCTs suggests that $2.15 \mathrm{~g} / \mathrm{d}$ phytosterols added in fat matrices lowers LDLc concentration by $8.8 \%$ [15]. However, daily intake of capsules containing $2 \mathrm{~g}$ phytosterols did not reduce total- or LDL-cholesterol significantly [16], this study emphasized the importance of phytosterols from daily diets in cholesterol lowering effect.

The daily intakes of total phytosterols usually range from 200 to $400 \mathrm{mg}$ in general population $[17,18]$ and higher daily intake of $500-1000 \mathrm{mg}$ can be reached by vegetarians $[19,20]$. However, in most RCTs, the health benefits are observed at a high dose of phytosterols intake (around $2 \mathrm{~g} / \mathrm{d}$ ), which cannot be achieved in habitual diets. In total, there are limited evidence limited evidence on the association of natural dietary intake of phytosterols and anthropometric parameters, blood glucose and serum lipid profiles. This study aims to examine the hypothesis that higher dietary phytosterols improves body weight and metabolic profile in healthy adults.

\section{Methods}

\section{Internet-based FFQ}

In large population, food frequency questionnaires (FFQs) were universally used by researchers [21]. However, impossibility of conducting traditional face-to-face FFQs during a short period make it inconvenient in researches due to time-consuming [22]. Therefore, a portable tool named Internet-based dietary questionnaire for Chinese (IDQC) has been designed and validated at Harbin Medical University by experts of nutrition, epidemiology and bio-statistics $[23,24]$. In IDQC, commonly eaten foods were divided into 16 categories (i.e., grains, potatoes, legumes, vegetables, fungus, fruits, seeds and nuts, livestock, poultry, dairy, eggs, fish, snacks, sugar, condiments, and beverages). Reference images of each food item's weight/volume were exhibited as references to assist the participants in making accurate estimation of food portions. Each participant had to choose the frequency and amount of each subtype of food groups. Finally, the questionnaires were uploaded to a secure website, which is free of access at http://www.yyjy365.org/diet.

\section{Study population}

To restrict the cost of the biochemical measurements and the length of the study, we randomly selected 912 participants from the database of previously published literature [25] (Additional file 1: Figure S1.). This sample size is sufficient to detect differences of the primary outcome between quartiles, at $95 \%$ power and 5\% level of significance $(0.24 \mathrm{mmol} / \mathrm{l}$ in $\mathrm{TC}$ and $0.24 \mathrm{mmol} / \mathrm{l}$ in LDLc). Online questionnaires including age, gender, occupation, education background, income, physical exercise, smoking, drinking and dietary habits during the past 6 months were completed by all participants as previously described [25]. Daily nutrients intakes were then calculated by using the computerized China food composition tables of 2009 [26].

In this study, the following exclusion criteria were applied: (1) missing data of dietary intake; (2) reported extremely low or high energy intake (i.e. $<800 \mathrm{kcal}$ $(3349 \mathrm{~kJ})$ or $>5000 \mathrm{kcal}(20,934 \mathrm{~kJ})$ for males; $<600 \mathrm{kcal}$ $(2512 \mathrm{~kJ})$ or $>4000 \mathrm{kcal}(16,747 \mathrm{~kJ})$ for females); (3) Diabetes diagnosis in routine physical examination; (4) Being on a diet in the past 6 months. The study complied with the Declaration of Helsinki and was approved by the Human Research Ethics Committee of the Harbin Medical University (approval code [2015] 006). Online informed consent was obtained from all participants.

\section{Estimation of phytosterols intake}

On the basis of dietary habits of Chinese residents, more than 160 types of food items (including vegetable oils, cereal and its products, beans and its products, vegetables, fruits, nuts and potatoes) in the Chinese food composition table were chosen for measurement. The contents of $\beta$ sitosterol, campesterol, stigmasterol, $\beta$-sitostanol and campestanol in food were analyzed at Institute of Nutrition and Food Safety, Chinese Centre for Disease Control and Prevention, Beijing, China, using gas chromatograph methods by Han et al. [27, 28]. The database of phytosterols concentrations were established and were linked to the questionnaire data, intake of phytosterols were then estimated using the IDQC. A supplementary table outlining the phytosterols contents of typical foods in Chinese was provided (Additional file 2: Table S1).

\section{Anthropometric measurements, cut-off points of overweight/ obesity and definition of abdominal obesity}

Height, bodyweight and waist circumference (WC) were measured by well-trained medical students. Body mass index (BMI) was calculated as body weight in kilograms divided by the square of the height in meters $\left(\mathrm{kg} / \mathrm{m}^{2}\right)$. Participants were asked to wear light, thin clothing and no shoes. Body weight and height were measured to the nearest $0.1 \mathrm{~kg}$ and $0.1 \mathrm{~cm}$. WC was measured midway between the lowest rib and the iliac crest with a flexible anthropometric tape on the horizontal plane with the participant in standing position, to the nearest of $0.1 \mathrm{~cm}$. After a $10 \mathrm{~min}$ rest in a sitting position, systolic blood pressure (SBP) and 
diastolic blood pressure (DBP) of participants were gauged using a standard mercury sphygmomanometer by nurses of the health examination center, mean values of three times were recorded. The BMI cut-off points in Chinese subjects for overweight $\left(24 \leq \mathrm{BMI}<28 \mathrm{~kg} / \mathrm{m}^{2}\right)$ and obesity (BMI $\geq$ $28 \mathrm{~kg} / \mathrm{m}^{2}$ ) were used in our study to define these states [29]. According to the 2006 Guidelines on Preservation and Control Overweight and Obesity in Chinese Adults classification [30], abdominal obesity was defined as $\mathrm{WC} \geq 85 \mathrm{~cm}$ in men and $W C \geq 80 \mathrm{~cm}$ in women.

\section{Serum collection and laboratory measurements}

Fasting blood samples were collected between 8:00 and 9:00 a.m. after fasting overnight. Then, each participant was asked to take $75 \mathrm{~g}$ glucose and postprandial blood samples were drawn $2 \mathrm{~h}$ later. FBG and $2 \mathrm{~h}-\mathrm{PG}$ were measured with a hand-held glucometer (ACCU-CHEK, Roche, Shanghai, China). Blood samples were centrifuged at $3000 \mathrm{rpm}$ for $15 \mathrm{~min}$ and the serum was used for laboratory measurements immediately. Serum triglyceride (TG), total cholesterol (TC), high density lipoprotein cholesterol (HDLc) and low density lipoprotein cholesterol (LDLc) were determined using a Roche Modular P800 Automatic Biochemical Analyzer (Roche Diagnostics, Mannheim, Germany). Coefficients of variations of lab measurements were presented in supplemental materials.

\section{Statistical analysis}

For descriptive statistics, means and SDs (or frequencies and percentages) were calculated across quartiles of dietary phytosterols and compared using one-way analysis of variance or chi-square test, as appropriate. Bivariate correlation analysis (without variants adjusted) and partial correlation analysis (with adjustment for energy intake) was performed to assess the association of dietary phytosterols and BMI, WC, SBP, DBP, FBG, 2 h-PG, serum TG, TC, HDLc and LDLc. To estimate the odds ratio (OR) and 95\% confidence interval (CI) of overweight/obesity and abdominal obesity between quartiles of dietary phytosterols, logistic regression model was used. Age, education, income, labor, exercise status, smoking habits, drinking habits, dietary carbohydrate, fat, protein, cholesterol and fiber intake were adjusted in three models. The statistical analyses were carried out using SAS software (version 9.1; SAS Institute, Cary, NC, USA) and $P<0.05$ was considered statistically significant.

\section{Results}

\section{Characteristics and dietary intakes of the study population}

The characteristics and dietary intakes of participants were summarized in Table 1. Participants of the 3rd quartile of dietary phytosterols were youngest. Participants of the 4th quartile of dietary phytosterols had a higher percentage of low income and low education level versus the first quartile.
For dietary intakes, energy, protein, fat, fiber and cholesterol intake increased through quartiles of dietary phytosterols. Finally, among individuals with higher intake of phytosterols, lower prevalence of overweight/obesity and abdominal obesity were observed.

\section{Anthropometric parameters, blood glucose and serum lipid profiles of participants}

BMI, WC, blood glucose and serum lipid profiles of participants among quartiles of dietary phytosterols were showed in Table 2. Compared with those in the first quartile of dietary phytosterols, participants of the 4th quartile had lower BMI, WC, SBP, DBP, TC and LDLc $(P<0.01$ for BMI and TC, $P<0.05$ for WC, SBP, DBP and LDLc). After stratified by gender, similar results were observed in men and women (all $P<0.05$ ). There is no significant difference of FBG, $2 \mathrm{~h}$ PG, TG and HDLc among quartiles of dietary phytosterols.

\section{Correlations between dietary phytosterols and anthropometric parameters, blood glucose and serum lipid profiles}

As shown in Table 3, we found negative correlations between total phytosterols and BMI, WC, SBP, DBP, TC and LDLc (all $P<0.05$ ). The associations were stronger with adjustment of total energy intake. After stratified by gender, similar trends were observed in male and female (all $P<0.05$ ). However, no significant associations between dietary phytosterols and FBG, 2 h-PG, TG and HDLc were observed.

\section{Correlations between dietary plant sterols and prevalence of obesity}

With adjustment for potential dietary and non-dietary cofounders (age, education, income, PAL, physical exercise, smoking and drinking status, dietary carbohydrate, fat, protein, fiber and cholesterol intake), we found higher dietary total phytosterols intake was linked with lower prevalence of overweight/obesity. Data was illustrated in Table 4, compared with the 1st quartile, the multivariable-adjusted ORs of overweight/obesity of the 4th quartile were $0.440(0.254$, $0.763)$ in overall population, $0.487(0.234,0.918)$ in men and $0.277(0.124,0.619)$ in women. (All $P<0.05)$.

\section{Correlations between dietary plant sterols and prevalence of abdominal obesity}

In this study, we have observed the reverse relationship between dietary phytosterols and abdominal obesity. As shown in Table 5, compared with the 1st quartile, the multivariable-adjusted ORs of abdominal obesity of the 4th quartile were $0.239(0.127,0.450)$; $0.344(0.144,0.819)$ and $0.321(0.140,0.571)$ in overall population, men and women, respectively (All $P<0.05$ ). Potential dietary and non-dietary cofounders (age, education, income, PAL, physical exercise, smoking and drinking status, dietary 
Table 1 Characteristics and dietary nutrients intake of participants by quartiles (Q) of total phytosterols intake

\begin{tabular}{|c|c|c|c|c|c|}
\hline \multirow[b]{2}{*}{ Characteristics } & \multicolumn{4}{|c|}{ Quartiles based on total phytosterols intake } & \multirow[b]{2}{*}{$P$} \\
\hline & Q1 & Q2 & Q3 & Q4 & \\
\hline Total, n & 228 & 228 & 228 & 228 & \\
\hline Age, y & $32.4 \pm 12.2 \mathrm{a}$ & $33.5 \pm 13.1 \mathrm{a}$ & $29.4 \pm 11.4 b$ & $33.2 \pm 12.6 a$ & 0.002 \\
\hline Gender, M/W & 109/119 & $88 / 140$ & 106/122 & $106 / 122$ & 0.179 \\
\hline Income per month & & & & & 0.027 \\
\hline$<2000$ yuan, $\mathrm{n}(\%)$ & $133(58.3)$ & $133(58.3)$ & $154(67.5)$ & $158(69.3)$ & \\
\hline 2000-5000 yuan, n (\%) & $86(37.7)$ & $92(40.4)$ & $70(30.7)$ & $64(28.1)$ & \\
\hline$\geq 5000$ yuan, $n(\%)$ & $9(3.9)$ & $3(1.3)$ & $4(1.8)$ & $6(2.6)$ & \\
\hline Education & & & & & $<0.001$ \\
\hline Under college, n (\%) & $46(20.2)$ & $52(22.8)$ & $54(23.7)$ & $72(31.6)$ & \\
\hline Bachelor, n (\%) & $162(71.1)$ & $166(72.8)$ & $170(74.5)$ & $152(66.7)$ & \\
\hline Master or doctor, n (\%) & $20(8.8)$ & $10(4.4)$ & $4(1.8)$ & $4(1.8)$ & \\
\hline PAL & & & & & 0.145 \\
\hline Light, n (\%) & $58(25.4)$ & $58(25.4)$ & $58(25.4)$ & $70(32.5)$ & \\
\hline Medium, n (\%) & $160(70.2)$ & $161(70.6)$ & $168(73.7)$ & $154(67.5)$ & \\
\hline Heavy, n (\%) & $10(4.4)$ & $9(3.9)$ & $2(0.9)$ & $4(1.8)$ & \\
\hline Exercise & & & & & 0.949 \\
\hline < 10 h/week, n (\%) & $101(44.3)$ & $94(41.2)$ & $88(38.6)$ & $92(40.4)$ & \\
\hline 10-20 h/week, n (\%) & $98(43.0)$ & $104(45.6)$ & $108(47.4)$ & $106(46.5)$ & \\
\hline$\geq 20$ h/week, n (\%) & $29(12.7)$ & $30(13.2)$ & $32(14.0)$ & $30(13.2)$ & \\
\hline Smoking ${ }^{a}$ & & & & & 0.072 \\
\hline Non-smoker, n (\%) & $206(90.4)$ & $207(90.8)$ & $210(92.1)$ & $194(85.1)$ & \\
\hline Current smoker, n (\%) & $22(9.6)$ & $21(9.2)$ & $18(7.9)$ & $34(14.9)$ & \\
\hline Drinking $^{a}$ & & & & & 0.636 \\
\hline Non-drinker, n (\%) & $182(79.8)$ & $184(80.7)$ & $184(80.7)$ & $192(84.2)$ & \\
\hline Current drinker, n (\%) & $46(20.2)$ & $44(19.3)$ & $44(19.3)$ & $36(15.8)$ & \\
\hline Overweight/obesity, n (\%) & $100(43.9)$ & $90(39.5)$ & $82(36.0)$ & $74(32.5)$ & 0.075 \\
\hline Abdominal obesity, n (\%) & $77(33.8)$ & $62(27.2)$ & $59(25.9)$ & $54(23.7)$ & 0.092 \\
\hline \multicolumn{6}{|l|}{ Dietary intakes } \\
\hline Energy, kcal & $2179.3 \pm 528.7 a$ & $2271.9 \pm 551.5 b$ & $2368.9 \pm 548.6 c$ & $2498.2 \pm 494.1 d$ & $<0.001$ \\
\hline Protein, g/d & $76.1 \pm 21.2 \mathrm{a}$ & $82.9 \pm 23.9 b$ & $86.9 \pm 24.9 b$ & $95.2 \pm 22.1 \mathrm{c}$ & $<0.001$ \\
\hline Fat, g/d & $60.2 \pm 23.0 \mathrm{a}$ & $69.5 \pm 23.7 b$ & $74.3 \pm 24.7 c$ & $86.4 \pm 21.7 d$ & $<0.001$ \\
\hline Carbohydrate, g/d & $344.9 \pm 93.6$ & $343.6 \pm 89.9$ & $353.0 \pm 91.7$ & $355.8 \pm 89.8$ & 0.399 \\
\hline Fiber, g/d & $14.4 \pm 3.9 a$ & $17.3 \pm 4.4 b$ & $19.5 \pm 4.9 c$ & $23.1 \pm 5.2 d$ & $<0.001$ \\
\hline Cholesterol, mg/d & $382.9 \pm 230.5 a$ & $461.1 \pm 266.9 b$ & $445.8 \pm 275.0 \mathrm{~b}$ & $504.2 \pm 260.4 c$ & $<0.001$ \\
\hline Total plant sterols, mg/d & $161.9 \pm 23.0$ & $231.3 \pm 20.1$ & $294.0 \pm 18.8$ & $383.0 \pm 54.4$ & $<0.001$ \\
\hline$\beta$-sitosterol, mg/d & $96.4 \pm 16.8 \mathrm{a}$ & $139.9 \pm 22.2 b$ & $187.9 \pm 27.9 c$ & $255.7 \pm 47.3 d$ & $<0.001$ \\
\hline campesterol, mg/d & $32.5 \pm 13.4 a$ & $48.8 \pm 20.4 b$ & $51.4 \pm 26.9 b$ & $57.9 \pm 29.2 c$ & $<0.001$ \\
\hline stigmasterol, mg/d & $12.5 \pm 5.4 a$ & $15.0 \pm 5.9 b$ & $17.8 \pm 7.5 c$ & $19.0 \pm 7.3 d$ & $<0.001$ \\
\hline$\beta$-sitostanol, mg/d & $9.2 \pm 4.4 a$ & $13.3 \pm 5.6 b$ & $18.5 \pm 6.6 c$ & $27.2 \pm 7.5 d$ & $<0.001$ \\
\hline campestanol, mg/d & $11.3 \pm 3.3 a$ & $14.4 \pm 4.0 \mathrm{~b}$ & $18.3 \pm 4.2 \mathrm{C}$ & $23.2 \pm 4.8 \mathrm{~d}$ & $<0.001$ \\
\hline
\end{tabular}

$P$ values are for differences across quartiles of total plant sterols intake; Data are mean $\pm S D$ or frequency (percentage), $a, b, c, d$, mean values with unlike letters were significantly different $(P<0.05)$

Abbreviations: PAL physical activity level

${ }^{a}$ There is no report of quitting smoking or quitting drinking in our population 
Table 2 Anthropometric parameters, blood glucose and serum lipid profiles of participants by quartiles (Q) of total phytosterols intake

\begin{tabular}{|c|c|c|c|c|c|}
\hline & Quartiles baseo & tytosterols intake & & & \\
\hline & $\overline{\mathrm{Q} 1}$ & Q2 & Q3 & Q4 & $P$ \\
\hline Overall, $\mathrm{n}$ & 228 & 228 & 228 & 228 & \\
\hline $\mathrm{BMI}, \mathrm{kg} / \mathrm{m}^{2}$ & $23.85 \pm 3.17$ & $23.53 \pm 3.44$ & $23.05 \pm 3.71^{*}$ & $22.67 \pm 2.76^{* *}$ & 0.001 \\
\hline$W C, \mathrm{~cm}$ & $80.31 \pm 10.21$ & $78.76 \pm 8.74$ & $78.45 \pm 9.67^{*}$ & $78.12 \pm 7.91^{*}$ & 0.044 \\
\hline $\mathrm{SBP}, \mathrm{mm} \mathrm{Hg}$ & $119.51 \pm 11.16$ & $117.13 \pm 12.42$ & $116.45 \pm 11.33$ & $115.04 \pm 10.14^{*}$ & 0.034 \\
\hline $\mathrm{DBP}, \mathrm{mm} \mathrm{Hg}$ & $78.74 \pm 8.92$ & $77.32 \pm 8.41$ & $76.72 \pm 8.93$ & $76.27 \pm 7.22^{*}$ & 0.046 \\
\hline $\mathrm{FBG}, \mathrm{mmol} / \mathrm{l}$ & $4.71 \pm 0.81$ & $4.68 \pm 0.73$ & $4.59 \pm 0.82$ & $4.62 \pm 0.78$ & 0.282 \\
\hline $2 \mathrm{~h}-\mathrm{PG}, \mathrm{mmol} / \mathrm{l}$ & $6.42 \pm 0.97$ & $6.35 \pm 0.81$ & $6.33 \pm 0.87$ & $6.27 \pm 0.96$ & 0.361 \\
\hline $\mathrm{TG}, \mathrm{mmol} / \mathrm{l}$ & $1.68 \pm 1.24$ & $1.73 \pm 1.31$ & $1.71 \pm 1.28$ & $1.75 \pm 1.38$ & 0.916 \\
\hline $\mathrm{TC}, \mathrm{mmol} / \mathrm{l}$ & $5.25 \pm 0.87$ & $5.17 \pm 0.78$ & $5.09 \pm 0.86$ & $5.01 \pm 0.90^{* *}$ & 0.004 \\
\hline $\mathrm{HDLc}, \mathrm{mmol} / \mathrm{l}$ & $1.26 \pm 0.33$ & $1.25 \pm 0.34$ & $1.29 \pm 0.29$ & $1.25 \pm 0.36$ & 0.289 \\
\hline LDLc, mmol/l & $2.55 \pm 0.83$ & $2.42 \pm 0.86$ & $2.39 \pm 0.79$ & $2.31 \pm 0.90^{*}$ & 0.042 \\
\hline Men, $\mathrm{n}$ & 102 & 102 & 102 & 103 & \\
\hline BMl, $\mathrm{kg} / \mathrm{m}^{2}$ & $23.91 \pm 3.09$ & $23.77 \pm 3.25$ & $23.41 \pm 3.36$ & $22.75 \pm 2.68^{*}$ & 0.016 \\
\hline$W C, \mathrm{~cm}$ & $83.45 \pm 9.26$ & $81.19 \pm 9.62$ & $79.63 \pm 9.18^{*}$ & $78.58 \pm 7.26^{*}$ & 0.024 \\
\hline $\mathrm{SBP}, \mathrm{mm} \mathrm{Hg}$ & $120.12 \pm 12.01$ & $118.03 \pm 11.45$ & $117.17 \pm 11.45$ & $115.03 \pm 9.98^{*}$ & 0.047 \\
\hline $\mathrm{DBP}, \mathrm{mm} \mathrm{Hg}$ & $79.11 \pm 7.92$ & $78.23 \pm 8.63$ & $77.87 \pm 8.95$ & $77.03 \pm 7.15^{*}$ & 0.045 \\
\hline $\mathrm{FBG}, \mathrm{mmol} / \mathrm{l}$ & $4.75 \pm 0.86$ & $4.81 \pm 0.78$ & $4.79 \pm 0.81$ & $4.72 \pm 0.91$ & 0.442 \\
\hline $2 \mathrm{~h}-\mathrm{PG}, \mathrm{mmol} / \mathrm{l}$ & $6.51 \pm 0.92$ & $6.66 \pm 0.98$ & $6.35 \pm 0.78$ & $6.24 \pm 0.86$ & 0.296 \\
\hline $\mathrm{TG}, \mathrm{mmol} / \mathrm{l}$ & $1.79 \pm 1.14$ & $1.73 \pm 1.21$ & $1.78 \pm 1.24$ & $1.76 \pm 1.41$ & 0.855 \\
\hline $\mathrm{TC}, \mathrm{mmol} / \mathrm{l}$ & $5.17 \pm 0.91$ & $5.06 \pm 0.89$ & $5.01 \pm 0.81$ & $4.95 \pm 0.88^{*}$ & 0.028 \\
\hline $\mathrm{HDLc}, \mathrm{mmol} / \mathrm{l}$ & $1.27 \pm 0.35$ & $1.26 \pm 0.38$ & $1.24 \pm 0.32$ & $1.23 \pm 0.37$ & 0.354 \\
\hline LDLc, mmol// & $2.44 \pm 0.86$ & $2.31 \pm 0.91$ & $2.25 \pm 0.77$ & $2.19 \pm 0.86^{*}$ & 0.034 \\
\hline Women, $\mathrm{n}$ & 125 & 126 & 126 & 126 & \\
\hline $\mathrm{BMI}, \mathrm{kg} / \mathrm{m}^{2}$ & $23.72 \pm 3.24$ & $23.41 \pm 3.31$ & $22.78 \pm 3.74^{*}$ & $22.45 \pm 2.66^{*}$ & 0.021 \\
\hline$W C, \mathrm{~cm}$ & $76.02 \pm 8.17$ & $74.28 \pm 8.21$ & $73.20 \pm 9.12^{*}$ & $72.89 \pm 7.31^{*}$ & 0.047 \\
\hline $\mathrm{SBP}, \mathrm{mm} \mathrm{Hg}$ & $118.23 \pm 10.93$ & $116.34 \pm 12.78$ & $114.96 \pm 11.61$ & $113.82 \pm 10.21^{*}$ & 0.038 \\
\hline $\mathrm{DBP}, \mathrm{mm} \mathrm{Hg}$ & $77.71 \pm 8.86$ & $76.25 \pm 8.52$ & $75.12 \pm 8.61$ & $74.78 \pm 7.31^{*}$ & 0.032 \\
\hline $\mathrm{FBG}, \mathrm{mmol} / \mathrm{l}$ & $4.68 \pm 0.82$ & $4.59 \pm 0.71$ & $4.41 \pm 0.78$ & $4.44 \pm 0.98$ & 0.341 \\
\hline $2 \mathrm{~h}-\mathrm{PG}, \mathrm{mmol} / \mathrm{l}$ & $6.31 \pm 0.91$ & $6.26 \pm 0.95$ & $6.31 \pm 0.82$ & $6.33 \pm 0.91$ & 0.458 \\
\hline $\mathrm{TG}, \mathrm{mmol} / \mathrm{l}$ & $1.58 \pm 1.31$ & $1.72 \pm 1.34$ & $1.66 \pm 1.22$ & $1.74 \pm 1.33$ & 0.545 \\
\hline $\mathrm{TC}, \mathrm{mmol} / \mathrm{l}$ & $5.34 \pm 0.76$ & $5.29 \pm 0.76$ & $5.18 \pm 0.92$ & $5.06 \pm 0.93^{*}$ & 0.013 \\
\hline HDLc, mmol/l & $1.24 \pm 0.32$ & $1.24 \pm 0.31$ & $1.33 \pm 0.29$ & $1.27 \pm 0.36$ & 0.128 \\
\hline LDLc, mmol//l & $2.67 \pm 0.81$ & $2.52 \pm 0.83$ & $2.46 \pm 0.81$ & $2.41 \pm 0.85^{*}$ & 0.044 \\
\hline
\end{tabular}

Abbreviations: $B M I$ body mass index, WC waist circumference, SBP systolic blood pressure, DBP diastolic blood pressure, FBG fasting blood glucose, $2 \mathrm{~h}$-PG $2 \mathrm{~h}$ postprandial glucose, TG triglyceridel, TC total cholesterol, HDLc high destiny lipoprotein cholesterol, $L D L C$ low destiny lipoprotein cholesterol

${ }^{*} P<0.05$; ${ }^{* *} P<0.01$ compared with the 1 st quartile

carbohydrate, fat, protein, fiber and cholesterol intake) were rectified.

\section{Discussion}

To our knowledge, this is the first Internet-based crosssectional study to investigate associations between dietary phytosterols and anthropometric parameters, blood glucose, serum lipid profiles and prevalence of overweight/ obesity and abdominal obesity among healthy subjects. The major finding of this study is that higher dietary phytosterols intake was associated with lower BMI, WC, blood pressure, serum TC and LDLc and lower prevalence of overweight/obesity and abdominal obesity in northern Chinese adults. A moderate dietary intake of total plant sterols was found $(267.5 \mathrm{mg} / \mathrm{d})$ in our population. Therefore, this sample can represent the general population. 
Table 3 Correlation analysis of dietary total phytosterols versus anthropometric parameters, blood glucose and serum lipid profiles

\begin{tabular}{|c|c|c|c|c|}
\hline & \multicolumn{4}{|c|}{ Total phytosterols intake, $\mathrm{mg} / \mathrm{d}$} \\
\hline & \multicolumn{2}{|c|}{ Unadjusted } & \multicolumn{2}{|c|}{ Adjusted $^{a}$} \\
\hline & $r$ & $P$ & $\bar{r}$ & $P$ \\
\hline \multicolumn{5}{|l|}{ Overall } \\
\hline $\mathrm{BMl}, \mathrm{kg} / \mathrm{m}^{2}$ & -0.181 & $<0.001$ & -0.226 & $<0.001$ \\
\hline$W C, \mathrm{~cm}$ & -0.106 & 0.001 & -0.167 & $<0.001$ \\
\hline $\mathrm{SBP}, \mathrm{mm} \mathrm{Hg}$ & -0.112 & $<0.001$ & -0.132 & $<0.001$ \\
\hline $\mathrm{DBP}, \mathrm{mm} \mathrm{Hg}$ & -0.109 & 0.002 & -0.134 & $<0.001$ \\
\hline $\mathrm{FBG}, \mathrm{mmol} / \mathrm{l}$ & -0.024 & NS & -0.033 & NS \\
\hline $2 \mathrm{~h}-\mathrm{PG}, \mathrm{mmol} / \mathrm{l}$ & -0.019 & NS & -0.023 & NS \\
\hline $\mathrm{TG}, \mathrm{mmol} / \mathrm{l}$ & -0.033 & NS & -0.041 & NS \\
\hline $\mathrm{TC}, \mathrm{mmol} / \mathrm{l}$ & -0.144 & $<0.001$ & -0.183 & $<0.001$ \\
\hline $\mathrm{HDLc}, \mathrm{mmol} / \mathrm{l}$ & -0.023 & NS & -0.029 & NS \\
\hline LDLc, mmol/l & -0.138 & $<0.001$ & -0.167 & $<0.001$ \\
\hline \multicolumn{5}{|l|}{ Men } \\
\hline $\mathrm{BMI}, \mathrm{kg} / \mathrm{m}^{2}$ & -0.212 & $<0.001$ & -0.243 & $<0.001$ \\
\hline$W C, \mathrm{~cm}$ & -0.164 & $<0.001$ & -0.206 & $<0.001$ \\
\hline $\mathrm{SBP}, \mathrm{mm} \mathrm{Hg}$ & -0.117 & 0.024 & -0.136 & 0.011 \\
\hline $\mathrm{DBP}, \mathrm{mm} \mathrm{Hg}$ & -0.112 & 0.031 & -0.140 & 0.023 \\
\hline $\mathrm{FBG}, \mathrm{mmol} / \mathrm{l}$ & -0.028 & NS & -0.037 & NS \\
\hline $2 \mathrm{~h}-\mathrm{PG}, \mathrm{mmol} / \mathrm{l}$ & -0.023 & NS & -0.029 & NS \\
\hline $\mathrm{TG}, \mathrm{mmol} / \mathrm{l}$ & -0.034 & NS & -0.044 & NS \\
\hline $\mathrm{TC}, \mathrm{mmol} / \mathrm{l}$ & -0.147 & 0.003 & -0.191 & $<0.001$ \\
\hline $\mathrm{HDLc}, \mathrm{mmol} / \mathrm{l}$ & -0.021 & NS & -0.023 & NS \\
\hline LDLc, mmol//I & -0.133 & 0.006 & -0.185 & $<0.001$ \\
\hline \multicolumn{5}{|l|}{ Women } \\
\hline $\mathrm{BMI}, \mathrm{kg} / \mathrm{m}^{2}$ & -0.158 & $<0.001$ & -0.210 & $<0.001$ \\
\hline$W C, \mathrm{~cm}$ & -0.087 & 0.047 & -0.122 & 0.006 \\
\hline $\mathrm{SBP}, \mathrm{mm} \mathrm{Hg}$ & -0.106 & 0.028 & -0.129 & 0.011 \\
\hline $\mathrm{DBP}, \mathrm{mm} \mathrm{Hg}$ & -0.105 & 0.042 & -0.119 & 0.033 \\
\hline $\mathrm{FBG}, \mathrm{mmol} / \mathrm{l}$ & -0.019 & NS & -0.024 & NS \\
\hline $2 \mathrm{~h}-\mathrm{PG}, \mathrm{mmol} / \mathrm{l}$ & -0.014 & NS & -0.018 & NS \\
\hline $\mathrm{TG}, \mathrm{mmol} / \mathrm{l}$ & -0.029 & NS & -0.031 & NS \\
\hline $\mathrm{TC}, \mathrm{mmol} / \mathrm{l}$ & -0.137 & 0.011 & -0.179 & $<0.001$ \\
\hline $\mathrm{HDLc}, \mathrm{mmol} / \mathrm{l}$ & -0.027 & NS & -0.033 & NS \\
\hline LDLc, mmol/l & -0.121 & 0.021 & -0.145 & 0.006 \\
\hline
\end{tabular}

Abbreviations: $B M I$ body mass index, WC waist circumference, SBP systolic blood pressure, DBP diastolic blood pressure, $F B G$ fasting blood glucose, $2 h$ $P G 2$ h-postprandial glucose, $T G$ triglyceride, $T C$ total cholesterol, HDLC high destiny lipoprotein cholesterol, LDLC low destiny lipoprotein cholesterol, NS no significance

${ }^{\mathrm{a}}$ Adjusting for total energy intake

Lifestyle, including dietary habits and physical exercises, could present a distinct effect on management of bodyweight and lipid/lipoprotein. Here, we generally found a dose-dependent inverse association between phytosterols intake from natural diet and BMI, WC, blood pressure,
TC and LDLc in northern Chinese adults. Our findings suggest that higher intake of phytosterols in natural diet may be favorable in the prevention of overweight/obesity and improve cholesterol metabolism. Therefore, reasonable advice of consuming more phytosterol-rich foods may be useful for these patients.

It has been established that high dose of phytosterols can significantly reduce blood cholesterol in RCTs [31]. However, it was still undecided whether low doses of phytosterols from natural diets were effective in management of serum cholesterol. In our reserch, we found that higher dietary phytosterols were related with lower serum TC and LDLc after adjustment for total energy intake. Similar results were observed in two large cross-sectional studies. In the European Prospective Investigation into Cancer and Nutrition (EPIC-Norfolk) study, a $289 \mathrm{mg} / \mathrm{d}$ or $281 \mathrm{mg} / \mathrm{d}$ (in men/women) increase of phytosterols intake was correlated to $4.1 \% / 2.4 \%$ decrease in serum TC and $3.5 \% / 3.0 \%$ decrease in LDLc, respectively [32]. Another study including 37,150 men and 40,502 women presents 2.6\%/3.5\% lower TC and 3.1\%/3.2\% lower LDLc in highest quintile in comparison with the lowest quintile of plant sterols in men and women, respectively [33].

The underlying mechanism of hypocholesterolemic activity of phytosterols was summarized in a recent review [34]. It is well accepted that phytosterols inhibit the intestinal absorption of dietary cholesterol due to their greater affinity for micelles [35]. Therefore, more cholesterol and its metabolites were excreted by feces. Recent studies also suggest that phytosterols might lower LDLc by upregulating intestinal cholesterol efflux transporters and receptormediated lipoprotein cholesterol uptake in response to the reduced supply of exogenous cholesterol [34]. Moreover, in high fat diet feeding hamsters, phytosterols supplementation leads to a remarkable increase in the biliary bile acid:cholesterol ratio, induces the expression of CYP7A1, which governs the synthesis of bile acid and controls its activity at the transcriptional level [36], and normalizes the expression of HNF4A, a key controller of bale acid metabolism [37, 38], indicating that phytosterols enhance bile acid synthesis.

Another important finding of this study was the lower SBP and DBP of the 4th quartile of dietary phytosterols than in the 1st quartile. The lower SBP was most likely interpreted by the lower body weight. The benefits of the decrease in blood pressure are apparent, because lower blood pressure has been shown to lower risk of cardiovascular morbidity [39]. Coker et al. reported that dietary supplementation of essential amino acids and phytosterols may reduce risk for metabolic syndrome and cardiovascular diseases by promoting the reductions of blood lipids and improving insulin resistance in overweight individuals with hypertriglyceridemia [40]. In our work, we did not observe significant correlations in FBG or 2 h-PG because, 
Table 4 Association between total phytosterols intake and prevalence of overweight/obesity

\begin{tabular}{|c|c|c|c|c|}
\hline Overall & Q1 & Q2 & Q3 & Q4 \\
\hline Participants, n & 228 & 228 & 228 & 228 \\
\hline No. of cases, n & 100 & 90 & 82 & 74 \\
\hline Intake, mg/d & 161.9 & 231.3 & 294 & 383 \\
\hline Crude & 1 & $0.835(0.575,1.212)$ & $0.719(0.493,1.047)$ & $0.615(0.420,0.900)^{*}$ \\
\hline Model 1 & 1 & $0.746(0.496,1.122)$ & $0.762(0.504,1.151)$ & $0.496(0.324,0.761)^{* * *}$ \\
\hline Model 2 & 1 & $0.708(0.462,1.085)$ & $0.711(0.445,1.136)$ & $0.440(0.254,0.763)^{* * *}$ \\
\hline Men & Q1 & Q2 & Q3 & Q4 \\
\hline Participants, n & 102 & 102 & 102 & 103 \\
\hline No. of cases, n & 49 & 44 & 34 & 32 \\
\hline Intake, mg/d & 157.3 & 233 & 381.4 & 301 \\
\hline Crude & 1 & $0.835(0.480,1.451)$ & $0.541(0.307,0.952)^{*}$ & $0.481(0.272,0.850)^{*}$ \\
\hline Model 1 & 1 & $0.752(0.412,1.373)$ & $0.552(0.294,1.035)$ & $0.509(0.274,0.946)^{*}$ \\
\hline Model 2 & 1 & $0.778(0.403,1.501)$ & $0.559(0.244,1.183)$ & $0.487(0.234,0.918)^{*}$ \\
\hline Women & Q1 & Q2 & Q3 & Q4 \\
\hline Participants, n & 125 & 126 & 126 & 126 \\
\hline No. of cases, n & 52 & 51 & 42 & 42 \\
\hline Intake, mg/d & 165.6 & 229.3 & 287.6 & 384.2 \\
\hline Crude & & $0.955(0.577,1.579)$ & $0.702(0.420,1.173)$ & $0.702(0.420,1.173)$ \\
\hline Model 1 & & $0.927(0.527,1.631)$ & $0.790(0.441,1.414)$ & $0.501(0.275,0.911)^{*}$ \\
\hline Model 2 & 1 & $0.758(0.416,1.380)$ & $0.537(0.275,1.048)$ & $0.277(0.124,0.619)^{* * *}$ \\
\hline
\end{tabular}

Model 1: adjusting for age, education, income, PAL, exercise status, smoking and drinking habits

Model 2: Model $1+$ dietary carbohydrate, fat, protein, fiber and cholesterol intake were adjusted

${ }^{*} P<0.05 ;{ }^{*} P<0.01$ compared with the 1 st quartile

Table 5 Association between total phytosterols intake and prevalence of abdominal obesity

\begin{tabular}{|c|c|c|c|c|}
\hline Overall & Q1 & Q2 & Q3 & Q4 \\
\hline Participants, n & 228 & 228 & 228 & 228 \\
\hline No. of cases, $n$ & 77 & 62 & 59 & 54 \\
\hline Intake, mg/d & 161.9 & 231.3 & 294 & 383 \\
\hline Crude & 1 & $0.732(0.491,1.093)$ & $0.685(0.457,1.025)$ & $0.609(0.404,0.918)^{*}$ \\
\hline Model 1 & 1 & $0.806(0.513,1.266)$ & $0.566(0.360,0.891)^{*}$ & $0.490(0.305,0.785)^{* * *}$ \\
\hline Model 2 & 1 & $0.512(0.302,0.868)^{*}$ & $0.423(0.259,0.691)^{* *}$ & $0.239(0.127,0.450)^{* * *}$ \\
\hline Men & Q1 & Q2 & Q3 & Q4 \\
\hline Participants, n & 102 & 102 & 102 & 103 \\
\hline No. of cases, $n$ & 51 & 43 & 36 & 36 \\
\hline Intake, mg/d & 157.3 & 233 & 381.4 & 301 \\
\hline Crude & 1 & $0.741(0.426,1.289)$ & $0.529(0.302,0.927)^{*}$ & $0.545(0.311,0.957)^{*}$ \\
\hline Model 1 & 1 & $0.657(0.355,1.215)$ & $0.520(0.303,0.955)^{*}$ & $0.510(0.293,0.951)^{*}$ \\
\hline Model 2 & 1 & $0.462(0.233,0.918)^{*}$ & $0.407(0.191,0.864)^{*}$ & $0.344(0.144,0.819)^{*}$ \\
\hline Women & Q1 & Q2 & Q3 & Q4 \\
\hline Participants, n & 125 & 126 & 126 & 126 \\
\hline No. of cases, $n$ & 25 & 23 & 20 & 18 \\
\hline Intake, mg/d & 165.6 & 229.3 & 287.6 & 384.2 \\
\hline Crude & 1 & $0.893(0.476,1.676)$ & $0.755(0.395,1.443)$ & $0.667(0.343,1.295)$ \\
\hline Model 1 & 1 & $0.738(0.354,1.539)$ & $0.672(0.305,1.480)$ & $0.341(0.151,0.770)^{*}$ \\
\hline Model 2 & 1 & $0.525(0.216,1.276)$ & $0.497(0.221,1.118)$ & $0.321(0.140,0.571)^{* *}$ \\
\hline
\end{tabular}

Model 1: adjusting for age, education, income, PAL, exercise status, smoking and drinking habits Model 2: Model $1+$ dietary carbohydrate, fat, protein, fiber and cholesterol intake were adjusted * $P<0.05$; ** $P<0.01$ compared with the 1 st quartile 
at least in part, diabetic patients were excluded from the study, and both FBG and $2 \mathrm{~h}$-PG were in normal ranges at baseline.

The major limitation of this study is the cross-sectional and retrospective design which might have limitations in the confirmation of causal relationship. Therefore, long term cohort studies for verification of this issue are needed. Secondly, we included only those subjects who lived in Harbin, in consideration of the large population and vast territory of China, we should be rigorous to extrapolate this result to the general population.

In spite of those defects, this is the first web-based FFQ study that has investigated this issue. In our previous study, there were significantly positive correlations in the dietary intakes of 9 food groups and 23 nutrients between the IDQC and 3-day diet records [24], these data suggested that the intake of phytosterols assessed by using IDQC might reflect a long-term and stable habitual intake of phytosterols from habitual diets in this population. We firstly reported that higher dietary phytosterols were associated with lower BMI, WC, blood pressure, serum TC and LDLc and lower prevalence of overweight/obesity and abdominal obesity, which provided practical significances in nutritional counseling as the importance for prevention of dyslipidemia, obesity and cardiovascular diseases. For overweight/obese and hypercholesterolemia clients, advice of consuming more plant sterols-rich foods may be useful.

\section{Conclusions}

Overall, our study firstly reported that dietary phytosterols were negatively associated with BMI, WC, SBP, DBP, serum TC and LDLc. Higher dietary phytosterols were also associated with lower prevalence of overweight/obesity and abdominal obesity. Further studies are needed to verify the causal association and explore the potential mechanism.

\section{Additional files}

Additional file 1: Flow of the study population. (JPEG 45 kb)

Additional file 2: Table S1. The phytosterols contents in commonly consumed foods of China. (DOCX $19 \mathrm{~kb}$ )

\footnotetext{
Abbreviations

2 h-PG: 2 h-postprandial glucose; BMl: Body mass index; Cl: Confidence interval; CVDs: Cardiovascular diseases; DBP: Diastolic blood pressure; FBG: Fasting blood glucose; FFQ: Food frequency questionnaire; HDLc: High density lipoprotein cholesterol; IDQC: Internet-based dietary questionnaire for Chinese; LDLc: Low density lipoprotein cholesterol; OR: Odds ratio; RCTs: Randomized controlled trials; SBP: Systolic blood pressure; TC: Total cholesterol; TG: Triglycerides; WC: Waist circumference
}

\section{Acknowledgements}

We would like to thank the respondents who voluntarily took part in this study.

\section{Funding}

This study was supported by the National Natural Science Fund of China (No. 81573133) and Nature Science Fund of Heilongjiang provience (No. H2016018).

\section{Availability of data and materials}

Data and all materials supporting this research are available from the corresponding author on reasonable request.

\section{Authors' contributions}

R-NF and C-HS were responsible for the study concept and design; Y-CL, P-PG, and $\mathrm{MZ}$ performed the experiment and collected the data; $\mathrm{Y}-\mathrm{CL}$ carried out the analysis and interpretation of data; Y-CL and C-LL wrote the paper; RL, X-NJ contributed to the critical revision of the manuscript; R-NF and C-HS were responsible for obtaining funds and supervision. All authors read and approved the final manuscript.

\section{Ethics approval and consent to participate}

The study complies with the Declaration of Helsinki and was approved by the Human Research Ethics Committee of the Harbin Medical University (approval code [2015] 006). Online informed consent was obtained from all participants.

\section{Consent for publication}

Not applicable.

Competing interests

The authors declare that they have no competing interests.

\section{Publisher's Note}

Springer Nature remains neutral with regard to jurisdictional claims in published maps and institutional affiliations.

\section{Author details}

${ }^{1}$ Department of Nutrition and Food Hygiene, School of Public Health, Harbin Medical University, Harbin, People's Republic of China. ${ }^{2}$ Department of General Surgery, the Second Affiliated Hospital of Harbin Medical University, Harbin, People's Republic of China. ${ }^{3}$ Department of Food and School Hygiene, Dalian Center for Disease Control and Prevention, Dalian, People's Republic of China.

Received: 14 November 2017 Accepted: 8 March 2018

Published online: 16 March 2018

References

1. Ng M, Fleming T, Robinson M, Thomson B, Graetz N, Margono C, Mullany EC, Biryukov S, Abbafati C, Abera SF, et al. Global, regional, and national prevalence of overweight and obesity in children and adults during 19802013: a systematic analysis for the global burden of disease study 2013. Lancet. 2014;384:766-81.

2. Kim SK, Kim HJ, Hur KY, Choi SH, Ahn CW, Lim SK, Kim KR, Lee HC, Huh KB, Cha BS. Visceral fat thickness measured by ultrasonography can estimate not only visceral obesity but also risks of cardiovascular and metabolic diseases. Am J Clin Nutr. 2004;79:593-9.

3. Lorenzo C, Okoloise M, Williams K, Stern MP, Haffner SM, San Antonio Heart S. The metabolic syndrome as predictor of type 2 diabetes: the San Antonio heart study. Diabetes Care. 2003;26:3153-9.

4. de Simone G, Devereux RB, Chinali M, Roman MJ, Best LG, Welty TK, Lee ET, Howard BV, Strong Heart Study I. Risk factors for arterial hypertension in adults with initial optimal blood pressure: the strong heart study. Hypertension. 2006;47:162-7

5. Howard BV, Ruotolo G, Robbins DC. Obesity and dyslipidemia. Endocrinol Metab Clin N Am. 2003:32:855-67.

6. De Pergola G, Silvestris F. Obesity as a major risk factor for cancer. J Obes. 2013;2013:291546.

7. Hu FB, Liu Y, Willett WC. Preventing chronic diseases by promoting healthy diet and lifestyle: public policy implications for China. Obes Rev. 2011;12:552-9.

8. Estruch R, Ros E, Martinez-Gonzalez MA. Mediterranean diet for primary prevention of cardiovascular disease. N Engl J Med. 2013;369:676-7. 
9. Choi JH, Woo HD, Lee JH, Kim J. Dietary patterns and risk for metabolic syndrome in Korean women: a cross-sectional study. Medicine (Baltimore). 2015;94:e1424

10. Weihrauch JL, Gardner JM. Sterol content of foods of plant origin. J Am Diet Assoc. 1978;73:39-47.

11. Normen AL, Brants HA, Voorrips LE, Andersson HA, van den Brandt PA Goldbohm RA. Plant sterol intakes and colorectal cancer risk in the Netherlands cohort study on diet and Cancer. Am J Clin Nutr. 2001;74:141-8.

12. Ribas SA, Sichieri R, Moreira ASB, Souza DO, Cabral CTF, Gianinni DT, Cunha DB. Phytosterol-enriched milk lowers LDL-cholesterol levels in Brazilian children and adolescents: double-blind, cross-over trial. Nutr Metab Cardiovasc Dis. 2017;(17):30225-9. https://doi.org/10.1016/j.numecd.2017.09. 010. [Epub ahead of print]

13. Baumgartner S, Mensink RP, Husche C, Lutjohann D, Plat J. Effects of plant sterol- or stanol-enriched margarine on fasting plasma oxyphytosterol concentrations in healthy subjects. Atherosclerosis. 2013;227:414-9.

14. Sialvera TE, Pounis GD, Koutelidakis AE, Richter DJ, Yfanti G, Kapsokefalou M, Goumas G, Chiotinis N, Diamantopoulos E, Zampelas A. Phytosterols supplementation decreases plasma small and dense LDL levels in metabolic syndrome patients on a westernized type diet. Nutr Metab Cardiovasc Dis. 2012;22:843-8.

15. Ras RT, Geleijnse JM, Trautwein EA. LDL-cholesterol-lowering effect of plant sterols and stanols across different dose ranges: a meta-analysis of randomised controlled studies. Br J Nutr. 2014;112:214-9.

16. Ottestad I, Ose L, Wennersberg MH, Granlund L, Kirkhus B, Retterstol K. Phytosterol capsules and serum cholesterol in hypercholesterolemia: a randomized controlled trial. Atherosclerosis. 2013;228:421-5.

17. Klingberg S, Andersson H, Mulligan A, Bhaniani A, Welch A, Bingham S, Khaw KT, Andersson S, Ellegard L. Food sources of plant sterols in the EPIC Norfolk population. Eur J Clin Nutr. 2008;62:695-703.

18. Sioen I, Matthys C, Huybrechts I, Van Camp J, De Henauw S. Consumption of plant sterols in Belgium: estimated intakes and sources of naturally occurring plant sterols and beta-carotene. Br J Nutr. 2011;105:960-6.

19. Vuoristo M, Miettinen TA. Absorption, metabolism, and serum concentrations of cholesterol in vegetarians: effects of cholesterol feeding. Am J Clin Nutr. 1994:59:1325-31.

20. Jenkins DJ, Kendall CW, Popovich DG, Vidgen E, Mehling CC, Vuksan V, Ransom TP, Rao AV, Rosenberg-Zand R, Tariq N, et al. Effect of a very-highfiber vegetable, fruit, and nut diet on serum lipids and colonic function. Metabolism. 2001:50:494-503.

21. Sublette ME, Segal-Isaacson CJ, Cooper TB, Fekri S, Vanegas N, Galfalvy HC, Oquendo MA, Mann JJ. Validation of a food frequency questionnaire to assess intake of n-3 polyunsaturated fatty acids in subjects with and without major depressive disorder. J Am Diet Assoc. 2011;111:117-23. e111-112

22. Haftenberger M, Heuer T, Heidemann C, Kube F, Krems C, Mensink GB. Relative validation of a food frequency questionnaire for national health and nutrition monitoring. Nutr J. 2010;9:36.

23. Feng RN, Du SS, Chen Y, Li Z, Zhang YF, Sun CH, Jiang YS. An internetbased food frequency questionnaire for a large Chinese population. Asia Pac J Clin Nutr. 2016;25:841-8.

24. Du SS, Jiang YS, Chen Y, Li Z, Zhang YF, Sun CH, Feng RN. Development and applicability of an internet-based diet and lifestyle questionnaire for college students in China: a cross-sectional study. Medicine (Baltimore). 2015;94:e2130.

25. Li YC, Li CL, Qi JY, Huang LN, Shi D, Du SS, Liu LY, Feng RN, Sun CH. Relationships of dietary histidine and obesity in northern Chinese adults, an internet-based cross-sectional study. Nutrients. 2016;8

26. Yang Y, Wang G, Guo X. China food composition tables. Beijing: Peking University Medical Press; 2009.

27. Han J, Yang Y, Feng M, Wang G. Analysis of phytosterol contents in Chinese plant food and primary estimation of its intake of people. Wei Sheng Yan Jiu. 2007:36:301-5

28. Han J, He M, Zhou S, Wang G. Analysis of phytosterol contents in food plant materials and Chinese traditional medicines. Wei Sheng Yan Jiu. 2009;38:188-91.

29. Zhou BF. Effect of body mass index on all-cause mortality and incidence of cardiovascular diseases-report for meta-analysis of prospective studies open optimal cut-off points of body mass index in Chinese adults. Biomed Environ Sci. 2002;15:245-52.

30. Hu J, Wallace DC, Jones E, Liu H. Cardiometabolic health of Chinese older adults with diabetes living in Beijing, China. Public Health Nurs. 2009;26:500-11.
31. Demonty I, Ras RT, van der Knaap HC, Duchateau GS, Meijer L, Zock PL, Geleijnse JM, Trautwein EA. Continuous dose-response relationship of the LDL-cholesterol-lowering effect of phytosterol intake. J Nutr. 2009; 139:271-84.

32. Andersson SW, Skinner J, Ellegard L, Welch AA, Bingham S, Mulligan A, Andersson $\mathrm{H}$, Khaw $\mathrm{KT}$. Intake of dietary plant sterols is inversely related to serum cholesterol concentration in men and women in the EPIC Norfolk population: a cross-sectional study. Eur J Clin Nutr. 2004;58:1378-85.

33. Klingberg S, Ellegard L, Johansson I, Hallmans G, Weinehall L, Andersson $H$, Winkvist A. Inverse relation between dietary intake of naturally occurring plant sterols and serum cholesterol in northern Sweden. Am J Clin Nutr. 2008;87:993-1001.

34. Plat J, Mensink RP. Plant stanol and sterol esters in the control of blood cholesterol levels: mechanism and safety aspects. Am J Cardiol. 2005:96:15D-22D.

35. De Smet E, Mensink RP, Plat J. Effects of plant sterols and stanols on intestinal cholesterol metabolism: suggested mechanisms from past to present. Mol Nutr Food Res. 2012;56:1058-72.

36. Kim M, Kim Y. Hypocholesterolemic effects of curcumin via upregulation of cholesterol 7a-hydroxylase in rats fed a high fat diet. Nutr Res Pract. 2010;4:191-5.

37. Inoue Y, Yu AM, Yim SH, Ma X, Krausz KW, Inoue J, Xiang CC, Brownstein MJ, Eggertsen G, Bjorkhem I, Gonzalez FJ. Regulation of bile acid biosynthesis by hepatocyte nuclear factor 4alpha. J Lipid Res. 2006;47:215-27.

38. Kalaany NY, Mangelsdorf DJ. LXRS and FXR: the yin and yang of cholesterol and fat metabolism. Annu Rev Physiol. 2006:68:159-91.

39. Patel P, Ordunez P, DiPette D, Escobar MC, Hassell T, Wyss F, Hennis A, Asma S, Angell S, Standardized Hypertension T, Prevention N. Improved blood pressure control to reduce cardiovascular disease morbidity and mortality: the standardized hypertension treatment and prevention project. J Clin Hypertens. 2016;18:1284-94.

40. Coker RH, Deutz NE, Schutzler S, Beggs M, Miller S, Wolfe RR, Wei J. Nutritional supplementation with essential amino acids and Phytosterols may reduce risk for metabolic syndrome and cardiovascular disease in overweight individuals with mild hyperlipidemia. J Endocrinol Diabetes Obes. 2015;3(2). Epub 2015 Apr 15

\section{Submit your next manuscript to BioMed Central and we will help you at every step:}

- We accept pre-submission inquiries

- Our selector tool helps you to find the most relevant journal

- We provide round the clock customer support

- Convenient online submission

- Thorough peer review

- Inclusion in PubMed and all major indexing services

- Maximum visibility for your research

Submit your manuscript at www.biomedcentral.com/submit
) Biomed Central 